$\underline{\text { Submitted to Materials Science and Engineering A (November 2017) }}$

\title{
Factors influencing superplasticity in the Ti-6Al-4V alloy processed by high-pressure torsion
}

\author{
Hamed Shahmir, Fariba Naghdi, Pedro Henrique R. Pereira, Yi Huang, Terence G. Langdon* \\ Materials Research Group, Faculty of Engineering and the Environment, \\ University of Southampton, Southampton SO17 1BJ, UK
}

\begin{abstract}
Two different initial microstructures, martensitic and lamellar, were developed in a Ti-6Al-4V alloy to examine their effect on the high temperature mechanical properties and superplasticity after high-pressure torsion (HPT). Significant grain refinement was achieved in both conditions with grain sizes after HPT processing of $\sim 30$ and $\sim 40 \mathrm{~nm}$, respectively. The nanocrystalline alloy in both conditions was subjected to mechanical testing at 923-1073 K with strain rates in the range from $10^{-3}$ to $10^{-1} \mathrm{~s}^{-1}$. The martensitic and lamellar alloys exhibited excellent ductility at these high temperatures including superplastic elongations at $973 \mathrm{~K}$ with maximum elongations of $815 \%$ and $690 \%$, respectively. The $f c c$ phase was stable at elevated temperatures in the martensitic alloy and the results suggests the $f c c$ phase may contribute to the superior superplastic properties of the martensitic alloy.
\end{abstract}

Keywords: High-pressure torsion; Phase transformation; Severe plastic deformation; Superplasticity; Ti-6Al-4V alloy.

*Corresponding author. Tel.: +442380593766; e-mail: langdon@ soton.ac.uk (T.G. Langdon) 


\section{Introduction}

Titanium alloys are well known for their potential as superplastic materials for use in a range of areas including aerospace engineering, power generation and in biomedical applications $[1,2]$. The $\alpha+\beta$ type of titanium alloys such as Ti- $6 \mathrm{Al}-4 \mathrm{~V}$ exhibit superplasticity when the alloys have suitable ratios of the $\alpha(h c p)$ and $\beta(b c c)$ phases and/or a fine-grained structure $[3,4]$. In practice, the existence of an $\alpha / \beta$ transformation in Ti-6Al- $4 \mathrm{~V}$ alloys means that a variety of microstructures may be achieved in this alloy through the use of different heat or thermomechanical treatments and these variations may significantly affect their mechanical properties. Superplastic flow in Ti$6 \mathrm{Al}-4 \mathrm{~V}$ alloys was achieved at temperatures higher than $1073 \mathrm{~K}$ when the volume fractions of the $\alpha$ and $\beta$ phases were approximately equal due to the low sliding resistance at the $\alpha / \beta$ phase boundaries which plays an important role in controlling superplasticity in the alloys with various $\alpha / \beta$ phase ratios $[5,6]$. Generally, the volume fraction of the $\beta$ phase in the Ti- $6 \mathrm{Al}-4 \mathrm{~V}$ alloy increases with increasing temperature and becomes rapid above $1173 \mathrm{~K}$ [7] where changes in the volume fractions of the $\beta$ phase are responsible for a transition from dislocation creep to superplasticity controlled by grain boundary sliding. Experiments show that at 1123 and $1173 \mathrm{~K}$, where the fraction of $\beta$ is optimal, dislocation activity is confined to the interiors of the $\beta$ grains, $\alpha$ lattice dislocations and recrystallization are not found and cavitation is minimal [8]. At lower temperatures, such as $973 \mathrm{~K}$, cavitation is observed due to the absence of the $\beta$ phase and at temperatures below $973 \mathrm{~K}$ there is generally no superplasticity in conventional Ti-6Al-4V alloys $[8]$.

Nevertheless, superplastic flow may be achieved in the Ti-6Al-4V alloy at even lower temperatures, below $973 \mathrm{~K}$, by introducing significant grain refinement to produce ultrafinegrained structures through the application of severe plastic deformation (SPD) [9-11]. In practice, high-pressure torsion (HPT) [12] is the optimum SPD technique for producing the smallest grain sizes and several reports are now available documenting the occurrence of superplasticity in nanocrystalline Ti-6Al-4V alloys processed using HPT [13-16]. It is anticipated that the 
appearance of even a small amount of the $\beta$-phase in a Ti-6Al-4V alloy would make a contribution to superplasticity by inhibiting significant grain growth and thereby promoting grain boundary sliding [15]. Thus, a nanostructured Ti-6Al-4V alloy produced by HPT showed superplastic behaviour with relatively high elongations (>500\%) during tensile testing at $923 \mathrm{~K}$ in the strain rate range of $10^{-4}$ to $10^{-3} \mathrm{~s}^{-1}[13,15]$ and an elongation of $676 \%$ was reported at a testing temperature of $998 \mathrm{~K}$ with an initial strain rate of $10^{-3} \mathrm{~s}^{-1}$ [15]. More recently, there is a report of an elongation of $790 \%$ at the lower testing temperature of $873 \mathrm{~K}$ using an initial strain rate of $10^{-4} \mathrm{~s}^{-1}[16]$.

Although several reports are now available describing the superplastic behaviour of the Ti6Al-4V alloy processed by HPT [13-16], there has been no systematic investigation to determine the effect of the initial microstructure on the high temperature mechanical behavior of the alloy. Depending on the prior heat treatment and cooling rate, the microstructures may be divided into different types. For very slow cooling rates from within the $\alpha+\beta$ region or above the $\beta$-transus temperature $(1263 \pm 20 \mathrm{~K})$, the $\beta$ phase primarily transforms into a globular type of $\alpha$. Increasing the cooling rate enhances the $\alpha$ nucleation rate at the $\beta$ grain boundaries and thereby enhances the formation and growth of $\alpha$ platelets into prior $\beta$ grains. The $\beta$ phase will fully or partly transform into a martensitic-type during high cooling rates and this martensite exists in the two different forms of $\alpha^{\prime}(h c p)$ and $\alpha^{\prime \prime}$ (orthorhombic) [17,18]. Most investigations to date have used an initial microstructure containing primary $\alpha$ and lamellar $\alpha+\beta$ [13-16] but in the present investigation a Ti-6Al-4V alloy was subjected to two different heat treatments in order to produce contrasting microstructures consisting of either almost fully martensitic $\alpha^{\prime}$ or fully lamellar $\alpha+\beta$. Accordingly, this research was initiated specifically to provide, for the first time, information on the significance of the initial microstructure prior to HPT processing on the high temperature mechanical properties attained within the Ti-6Al-4V alloy.

\section{Experimental material and procedures}

The experiments were conducted on a Ti-6Al-4V alloy (composition in wt $\%$ ) with the 
material divided into two separate batches for different heat treatments. The first batch was solution annealed at $1273 \mathrm{~K}$ for 30 min followed by water quenching to give a martensitic $\alpha^{\prime}$ microstructure. The second batch was solution annealed at $1223 \mathrm{~K}$ for $45 \mathrm{~min}$ followed by air cooling to room temperature, stress relief annealing at $873 \mathrm{~K}$ for $3 \mathrm{~h}$ and furnace cooling to give a lamellar $(\alpha+\beta)$ microstructure. Following the initial heat treatments, disks with thicknesses of $\sim 0.8 \mathrm{~mm}$ and diameters of $10 \mathrm{~mm}$ were processed by HPT at room temperature under an applied pressure of $P=6.0 \mathrm{GPa}$ using a rotation speed of $1 \mathrm{rpm}$ through totals of 10 revolutions under quasi-constrained conditions [19].

The initial microstructures were examined by optical microscopy (OM) after grinding, polishing using a $40 \mathrm{~nm}$ colloidal silica suspension and then etching with a solution of $88 \mathrm{~mL}$ $\mathrm{H}_{2} \mathrm{O}, 10 \mathrm{~mL} \mathrm{HNO}_{3}$ and $2 \mathrm{~mL} \mathrm{HF}$. Foils for transmission electron microscopy (TEM) were prepared after HPT using a focused ion beam (FIB) Zeiss Nvision 40 FIB facility at $3 \mathrm{~mm}$ from the disk centres in the normal sections of the disks so that the normals of the images lay in the shear direction. The TEM micrographs were obtained using a JEOL JEM-3010 microscope operating under an accelerating voltage of $300 \mathrm{kV}$. Each HPT disk was polished to a mirror-like quality and hardness measurements were taken using a Vickers microhardness tester with a load of $500 \mathrm{gf}$ and dwell times of $10 \mathrm{~s}$. The average microhardness values, Hv, were measured along randomly selected diameters on each disk with the measurements taken at intervals of $\sim 0.5 \mathrm{~mm}$ and at every point the local value of $\mathrm{Hv}$ was obtained from an average of four separate hardness measurements.

Electro-discharge machining was used to cut two miniature tensile specimens from symmetric off-centre positions in each disk, thereby avoiding the inhomogeneities associated with the limited straining around the disk centres [20]. These specimens had gauge dimensions of $1.1 \times 1.0 \times 0.6 \mathrm{~mm}^{3}$. The mechanical properties were examined at temperatures of 923 and $1023 \mathrm{~K}$ using an initial strain rate of $1.0 \times 10^{-2} \mathrm{~s}^{-1}$ and at $973 \mathrm{~K}$ using initial strain rates in the range $1.0 \times 10^{-3}$ to $1.0 \times 10^{-1} \mathrm{~s}^{-1}$. At least two samples were tested for each condition. The stress- 
strain curves were plotted for each specimen and the ultimate tensile strengths were derived from the curves. The elongations to failure were estimated by carefully measuring the gauge lengths before and after tensile testing.

The phase constituents were determined using X-ray diffraction (XRD) (Rigaku SmartLab) employing $\mathrm{Cu} \mathrm{K} \alpha$ radiation (wavelength $\lambda=0.154 \mathrm{~nm}$ ) at $45 \mathrm{kV}$ and a tube current of $200 \mathrm{~mA}$. The XRD measurements were performed over an angular $2 \theta$ range from $30^{\circ}$ to $90^{\circ}$ using a scanning step of $0.01^{\circ}$ and a scanning speed of $2^{\circ} \min ^{-1}$. The analysis using XRD was conducted using sample areas with diameters of $\sim 3 \mathrm{~mm}$ located near the edges of the disks. The microstructures of samples after tensile testing at $973 \mathrm{~K}$ were characterized in the gauge and grip regions using electron backscattered diffraction (EBSD) with a JSM6500F thermal field emission scanning electron microscope (SEM). The EBSD patterns were collected using step sizes of 0.2 $\mu \mathrm{m}$ for the samples pulled to failure at $973 \mathrm{~K}$. Low-angle grain boundaries (LAGBs) were taken as boundaries with misorientation differences between adjacent measuring points within the range from $2^{\circ}$ to $15^{\circ}$ and high-angle grain boundaries (HAGBs) had misorientation differences of more than $15^{\circ}$. A clean-up procedure including grain dilatation and grain confidence index standardization was performed on each EBSD image such that the total numbers of modified points were less than $20 \%$ for all measured points.

\section{Experimental results}

\subsection{Microstructures before and after HPT processing}

The microstructure of the material after solution annealing at $1273 \mathrm{~K}$ for $30 \mathrm{~min}$ followed by water quenching is shown in Fig. 1(a). Thus, the coarse prior $\beta$ grains, with an average size of $\sim 500 \mu \mathrm{m}$, were fully transformed to $\alpha^{\prime}$ martensite and the microstructure shows martensitic laths with different orientations and average lath thicknesses of $\sim 0.8 \mu \mathrm{m}$. Figure 1(b) shows the microstructure after solution annealing at $1223 \mathrm{~K}$ for $45 \mathrm{~min}$ followed by air cooling to room temperature, stress relief annealing at $873 \mathrm{~K}$ and furnace cooling. For this condition, there is a lamellar $(\alpha+\beta)$ structure with different orientations distributed throughout the microstructure and 
with the retained $\beta$ phase lying between the $\alpha$ platelets. This microstructure consists of prior- $\beta$ grains with an average size of $\sim 500 \mu \mathrm{m}$, colony size parallel-oriented $\alpha$-phase lamellae of 200 $\mu \mathrm{m}$ and an $\alpha$ lamellae lath width of $\sim 1.5 \mu \mathrm{m}$. The microstructure of the $\alpha^{\prime}$ alloy after HPT through 10 turns is shown in Fig. 1(c) at a region $\sim 3 \mathrm{~mm}$ from the disk centre. The microstructure consists mainly of reasonably equiaxed grains with an average size of $\sim 30 \mathrm{~nm}$ and with the fringe contrast implying that highly dense dislocations are accumulated in the microstructure. Figure 1(d) illustrates the microstructure of the HPT-processed $\alpha+\beta$ alloy at the same position in the disk. This microstructure consists of an array of ultrafine equiaxed grains having an average size of $\sim 40 \mathrm{~nm}$ with grains having an irregular shape with sharp corners and many grains surrounded by boundaries that are wavy and not well delineated. These equiaxed grains appear to be formed by the fragmentation of elongated grains and the heterogeneous contrasts within the grains are caused by defects such as dislocations.

The results for the Vickers microhardness measurements on the $\alpha^{\prime}$ and $\alpha+\beta$ alloys after HPT are shown in Fig. 2 with the average values of Hv plotted along each disk diameter and with the lower dashed lines at $\mathrm{Hv} \approx 340$ and $\sim 290$ corresponding to the initial hardness values before HPT for the $\alpha^{\prime}$ and $\alpha+\beta$ alloys, respectively. It is clear that for both alloy conditions the hardness after HPT is significantly higher than before HPT. Thus, in Fig. 2 for the $\alpha^{\prime}$ alloy, there is essentially an increase up to $\mathrm{Hv} \approx 390$ at the edge of the disk after 10 turns whereas the hardness increases only to $\mathrm{Hv} \approx 355$ in the centre. The results confirm that it was not possible to produce a fullyhomogeneous hardness distribution after 10 turns and there are significantly lower hardness values within a radius of $<1 \mathrm{~mm}$ around the centre of the disk. The same trend is visible in Fig. 2 for the $\alpha+\beta$ alloy where the hardness at the edge increases to $\mathrm{Hv} \approx 350$ but the hardness is $\mathrm{Hv}$ $\approx 320$ in the centre. It is concluded from these data that the microharndess of the martensitic alloy is higher than for the lamellar alloy both before and after HPT processing.

\subsection{Mechanical properties at elevated temperatures}

Figure 3 shows the engineering stress-engineering strain curves after tensile deformation at 
temperatures of 923,973 and $1023 \mathrm{~K}$ with an initial strain rate of $1.0 \times 10^{-2} \mathrm{~s}^{-1}$ after HPT for (a) the $\alpha^{\prime}$ and (b) the $\alpha+\beta$ alloys. These curves show hardening in the initial stage, a peak stress and then gradual softening. The total elongations to failure are at a maximum at $973 \mathrm{~K}$ there are lower elongations at both lower and higher temperatures. Additional stress-strain curves are shown in Fig. 4 after testing at $973 \mathrm{~K}$ for initial strain rates from $1.0 \times 10^{-3}$ to $1.0 \times 10^{-1} \mathrm{~s}^{-1}$ for (a) the $\alpha^{\prime}$ and (b) the $\alpha+\beta$ alloy. It is evident that the total elongations to failure increase with decreasing stain rate and these elongations are consistently higher for the martensitic alloy.

The maximum total elongations recorded in these experiments after HPT under identical processing conditions was $815 \%$ and $690 \%$ for the $\alpha^{\prime}$ and $\alpha+\beta$ samples, respectively. Both of these values exceed the minimum tensile elongation of $400 \%$ which is a requirement for true superplastic flow [21]. It is important to note also that excellent superplastic elongations occur in the $\alpha^{\prime}$ alloy at a strain rate of $10^{-2} \mathrm{~s}^{-1}$ which confirms the occurrence of high strain rate superplasticity [22] whereas in the $\alpha+\beta$ alloy the elongation at $10^{-2} \mathrm{~s}^{-1}$ is $410 \%$ which is only marginally within the superplastic regime. Moreover, the experimental range of strain rates was not sufficient to clearly reveal the three regions of flow generally associated with superplastic alloys where the measured elongations decrease at both low and high strain rates [23].

Using data from Fig. 4, Fig. 5 shows the flow stress plotted logarithmically against the strain rate where the stress values decrease with decreasing strain rate and the measured strain rate sensitivities, $m$, are $\sim 0.33$ over two orders of magnitude of strain rate for the martensitic alloy and $\sim 0.27$ over a similar range for the lamellar alloy. These values of $m$ are low by comparison with conventional superplasticity where experiments generally give, and theory predicts, a value of $m \approx 0.5$ [24].

\subsection{Microstructures after high temperature deformation}

Figure 6 shows the X-ray diffraction patterns in the grip sections of (a) the $\alpha^{\prime}$ and (b) the $\alpha+\beta$ alloys for the initial condition (annealed), and in the grip sections after HPT and tensile testing at 923,973 and $1023 \mathrm{~K}$ using an initial strain rate of $1.0 \times 10^{-3} \mathrm{~s}^{-1}$. As anticipated, the 
microstructure of the initial $\alpha^{\prime}$ alloy in Fig. 6(a) consists only of martensite with a main peak at (101) $\alpha / \alpha^{\prime}$ whereas the microstructure of the initial $\alpha+\beta$ alloy in Fig. 6(b) shows $\alpha$-phase peaks with a main peak at $(101)_{\alpha / \alpha^{\prime}}$ and a peak corresponding to the $(110)_{\beta}$ plane at $2 \theta \approx 39.6^{\circ}$ which confirms the existence of the $\beta$-phase in the microstructure. The volume fraction of the $\beta$-phase in the heattreated condition was estimated as only $\sim 6 \%$ using standard procedures [25].

The XRD patterns of the martensitic alloy after HPT processing in Fig. 6(a) show clearly the appearance of new peaks at $2 \theta=44.5^{\circ}$ and $2 \theta=64.4^{\circ}$ marked with open inverted triangles, and these peaks correspond to the (200) and (220) planes of the $f c c$ structure. The volume fraction of the $f c c$ phase was estimated, again using standard procedures [25], as $\sim 40 \%$ after HPT through 10 turns. However, there is no evidence for the presence of $f c c$ or $\beta$ phases in the X-ray diffraction patterns of the $\alpha+\beta$ alloy after HPT processing. Thus, according to the initial condition of this alloy which consisted of $\alpha$ and $\beta$ phases, there is a dissolution of the $\beta$-phase during HPT processing which is consistent with another report [11]. The XRD patterns of the severelydeformed samples show that the peak corresponding to the $(110)_{\beta}$ plane at $2 \theta \approx 39.6^{\circ}$ appears in both alloys after holding at elevated temperatures and the volume fractions of the $\beta$-phase in both alloys increases with increasing temperature but the volume fractions of the $\beta$-phase remain at less than $6 \%$ under all conditions. It is apparent from Fig. 6(a) that the $f c c$-phase is stable at high temperatures but the intensity of this phase decreases significantly by holding at high temperatures by comparison with the HPT-processed condition. The volume fraction of the $f c c$ phase after holding at high temperatures was estimated as $\sim 10 \%$.

SEM images are shown in Fig. 7 for the $\alpha^{\prime}$ alloy after tensile testing at $973 \mathrm{~K}$ with an initial strain rate of $1.0 \times 10^{-3} \mathrm{~s}^{-1}$, corresponding to the maximum elongation of $\sim 815 \%$, (a) in the gauge section and (b) in the grip region. These images show that the microstructures of the sample consist of equiaxed fine grains after superplastic flow in both regions of the sample and, in addition to primary $\alpha$, there are some grains with lamellar $\alpha+\beta$ microstructures which are surrounded by $\alpha$ grains. The average grain sizes for this condition were measured as $\sim 1.5 \mu \mathrm{m}$ for 
both sections.

Figure 8 shows the EBSD-orientation images of tensile specimens of $(a, b)$ the martensitic and $(\mathrm{c}, \mathrm{d})$ the lamellar alloys after testing at $973 \mathrm{~K}$ with an initial strain rate of $1.0 \times 10^{-3} \mathrm{~s}^{-1}$ for the gauge sections on the left and within the grip area on the right: information on the measured grain sizes, $d$, the fractions of HAGBs and the corresponding pole figures for the basal $\{0001\}$ planes are also included on each image and the tensile directions lie horizontally. These specimens in Figs 8(a) and (c) correspond to tensile elongations of $815 \%$ and $690 \%$ which are the maximum values for the $\alpha^{\prime}$ and $\alpha+\beta$ samples, respectively. It is apparent that homogeneous equiaxed microstructures with average grain sizes close to $\sim 1.6 \mu \mathrm{m}$ and random crystallographic orientations were present in both gauge section after testing at $973 \mathrm{~K}$, whereas in the grip sections the microstructures tend to be elongated with preferred crystallographic orientations. A comparison of the deformed and undeformed microstructures in Figs 8 (a,c) and (b,d), respectively, reveals the presence of slightly larger grains in the gauge section by comparison with the grip section but with no significant difference in the volume fractions of HAGBs in the deformed and the undeformed microstructures. In practice, the grain size of the martensitic alloy at the gauge and grip sections appears to be slightly smaller than in the lamellar alloy.

\section{Discussion}

\subsection{Microstructural evolution during HPT processing and tensile testing}

Two different initial microstructures in the Ti-6Al-4V alloy, martensitic $\alpha^{\prime}$ and lamellar $(\alpha+\beta)$, were subjected to processing by HPT and the results reveal different hardness values and different final microstructures. Thus, the hardness is higher and the grain size is smaller for the $\alpha^{\prime}$ alloy by comparison with the $\alpha+\beta$ alloy so that the different initial microstructures have a significant effect on the processed structures. In practice, the martensitic microstructure contains high levels of residual stress, many dislocations and stacking faults with a few platelets containing twins due to the shear transformation, together with a supersaturated chemical composition [26]. In addition, the initial microstructures have a high volume fraction of 
boundaries in the $\alpha^{\prime}$ and $\alpha+\beta$ structures and these boundaries probably act as nucleation sites for rapid grain fragmentation and subgrain formation during the initial stages of HPT processing.

Twining plays a major role in the grain refinement, at least in the early stages of deformation in coarse-grained hcp-Ti alloys, and the introduction of extra interfaces within the grains during deformation twinning leads to significant grain refinement following the saturation of twinning [27-29]. During further straining, new deformation mechanisms such as dislocation slip and/or phase transformation are activated to accommodate the deformation. The present results suggest that the $h c p$ to $f c c$ phase transformation plays an important role in accommodating the constrained deformation in the martensitic alloy. The results show clearly that the single $\alpha^{\prime}$-phase changes to a dual $\alpha^{\prime}+f c c$ phase and the dual $\alpha+\beta$ phase changes to a single $\alpha$ phase during HPT processing through 10 turns. In earlier studies it was suggested that the existence of a high volume fraction of boundaries in the martensitic alloy, together with a substructure containing predominately dislocations and stacking faults with a few platelets containing twins, promotes grain refinement and the formation of the $f c c$ phase during HPT processing [30,31].

The results show that the heavily-deformed $\alpha^{\prime}$ and $\alpha$ microstructures transform to equilibrium $\alpha$ and $\beta$ when holding the samples at the testing temperatures and therefore there are phase transformations of the type $\alpha^{\prime}+f c c \rightarrow \alpha+\beta+f c c$ in the former and $\alpha \rightarrow \alpha+\beta$ in the latter. It was reported earlier that the fine precipitation of the $\alpha$ and $\beta$-phases from a fully martensitic structure occurs by a nucleation and growth process controlled by atom diffusion at martensite plate boundaries or at internal structures such as twins [32]. The volume fraction of the $\beta$-phase in both alloys increases by increasing the testing temperature but this investigation reveals a very low volume fraction of $\beta$-phase $(<6 \%)$ in the HPT-processed samples in both alloys after holding at high temperatures. The results also show that the $f c c$-phase is stable even after holding at 923$1023 \mathrm{~K}$ and the volume fraction of this phase is $\sim 10 \%$ at these temperatures.

\subsection{The importance of superplastic deformation in the martensitic and lamellar alloys}

The results confirm that the HPT-processed martensitic and lamellar Ti-6Al-4V alloys both 
exhibit superplastic elongations (>400\%) when testing at temperatures of 923 to $1023 \mathrm{~K}$ but it is apparent from Fig. 4 that the elongations are significantly higher in the martensitic alloy. The occurrence of superplastic elongations suggests that grain boundary sliding (GBS) occurs in the martensitic and lamellar alloys at these high temperatures [33]. This is consistent with Figs 7 and 8 where there are fine and equiaxed microstructures both in the undeformed grip regions and in the deformed gauge sections. These microstructures also reveal negligible dynamic coarsening when testing at $973 \mathrm{~K}$ with an initial strain rate of $1.0 \times 10^{-3} \mathrm{~s}^{-1}$.

The $\beta$-phase precipitation, which is accelerated after holding at the testing temperature following SPD, acts as an accommodation mechanism and contributes to the enhancement of superplasticity in both alloys. Thus, in Ti-6A1-4V alloy the appearance of even a small amount of $\beta$-phase during heating also makes a contribution to superplasticity by inhibiting significant grain growth and promoting GBS [14]. In addition, $\beta$ is softer than $\alpha$ at elevated temperatures $[34,35]$ due to a higher diffusivity and the presence of more active slip systems. Therefore, it is reasonable to assume that the volume fraction of $\beta$ plays role in determining the dominant flow mechanism [8]. It is important to note also that for the martensitic alloy the $f c c$-phase is stable in high temperature deformation and it appears that the existence of $\sim 10 \%$ fcc-phase during mechanical testing at high temperatures also contributes to superplastic flow by inhibiting grain growth and promoting GBS. The $f c c$ phase has a higher number of active slip systems than the $\beta$ and $\alpha$ phases and this will assist in the accommodation of GBS through intragranular slip.

\subsection{Significance of the measured strain rate sensitivity}

It is shown in Fig. 5 that the measured values of the strain rate sensitivity were $\sim 0.33$ and $\sim 0.27$ in the $\alpha^{\prime}$ and $\alpha+\beta$ alloys, respectively. These values are significantly lower than the anticipated value of $m \approx 0.5$ in the theoretical model for superplasticity [24] but the result is similar to the value of $m \approx 0.33$ for flow where dislocation glide is the rate-controlling process [36]. Nevertheless, the elongations to failure are much higher than those attained in any metals deforming by viscous glide where a recent review shows the maximum reported elongations are 
never more than $\sim 300 \%$ [21]. Furthermore, similar values of the stain rate sensitivity have been reported in other Ti-6Al-4V alloys processed to produce ultrafine-grained microstructures. For example, there are values of $m \approx 0.34$ after processing by equal-channel angular pressing (ECAP) to produce a grain size of $0.3 \mu \mathrm{m}$ and then testing at $973 \mathrm{~K}$ with a strain rate of $1 \times 10^{-4} \mathrm{~s}^{-1}$ to give an elongation of $474 \%$ [10] and $m \approx 0.3$ using multi-axial forging to produce a grain size of $0.3 \mu \mathrm{m}$ and then testing at $873 \mathrm{~K}$ with a strain rate of $5 \times 10^{-4} \mathrm{~s}^{-1}$ to give an elongation of $500 \%$ [37]. All of these elongations are within the superplastic regime and yet the strain rate sensitivities are unusually low.

A similar result was reported very recently for a $\mathrm{CoCrFeNiMn}$ high-entropy alloy where there was a measured value of $m \approx 0.31$ with superplastic elongations up to $>600 \%$ and the low value of $m$ was attributed to the occurrence of extensive grain growth during the tensile testing where the grains grew from $\sim 10 \mathrm{~nm}$ to $\sim 1.0 \mu \mathrm{m}$ [38]. This means that the grain size remained within the superplastic regime despite grain growth by two orders of magnitude and this contrasts with conventional superplastic alloys where the grain sizes are generally of a few micrometers and any grain growth takes the material outside of the superplastic range. As noted earlier, the occurrence of very extensive grain growth and microstructural instability will effectively displace the experimental points in a logarithmic plot of stress against strain rate and lead to an erroneously low value for the measured strain rate sensitivity [38]. The same explanation applies also for the present investigation on the Ti-6Al-4V alloy where the initial grain sizes after HPT were $\sim 30-40 \mathrm{~nm}$ but, as shown in Fig.8, the grain sizes after tensile testing were $\sim 1.5-1.7 \mu \mathrm{m}$ so that again the grain sizes remain in the superplastic regime.

\subsection{Significance of the initial microstructure on the superplastic elongations}

To provide a direct comparison with earlier published data on superplasticity of the Ti-6Al4V alloy after HPT processing, Table 1 summarizes the results reported to date for various experimental parameters including the initial microstructures and the associated total elongations to failure, $\delta$. All results show high superplastic elongations but the elongation of $815 \%$ obtained 
in the present investigation is the highest achieved to date. However, all earlier investigations used samples with initial microstructures containing a mix of primary $\alpha$ and lamellar $\alpha+\beta$ [1316] whereas the present investigation used two separate initial microstructures of either lamellar $(\alpha+\beta)$ or martensite $\left(\alpha^{\prime}\right)$.

The present results clearly display the effect of the initial microstructure on superplasticity in the Ti-6Al-4V alloy. Both microstructures produced significant grain refinement through HPT processing with average grain sizes of $\sim 30$ and $\sim 40 \mathrm{~nm}$ in the $\alpha^{\prime}$ and $\alpha+\beta$ alloys, respectively. These grain sizes are exceptionally small since the smallest grain size reported earlier for a Ti$6 \mathrm{Al}-4 \mathrm{~V}$ alloy was $d=75 \pm 15 \mathrm{~nm}$ for an alloy containing $25 \% \alpha$-phase and 75\% lamellar $(\alpha+\beta)$ which was then processed by HPT for up to 20 turns [16]. It is apparent that the initial grain size of the martensitic alloy is smaller than the lamellar alloy and this will contribute to the higher elongations for this initial condition. In addition, the formation of the $f c c$-phase in the martensitic alloy during HPT may be beneficial in improving the superplastic properties. The results demonstrate that the grain sizes of the HPT-processed samples easily fulfill the requirement for superplasticity since the grain size is retained within the superplastic regime for both initial conditions even after exposing to high testing temperatures. The results show clearly that the HPT-processed martensitic alloy exhibits superior superplastic properties by comparison with the HPT-processed lamellar alloy.

\subsection{Comparison with superplasticity in Ti-6Al-4V alloys using other processing techniques}

Although the grain size achieved in the martensitic alloy was $\sim 30 \mathrm{~nm}$ after HPT processing and this produced exceptional superplasticity with a record elongation of $815 \%$, inspection shows this elongation is significantly smaller than reported in other investigations of the Ti-6Al-4V alloy using other processing techniques. For example, an elongation of $1000 \%$ was achieved in this alloy processed by multi-axial forging to produce a grain size in the range of $0.1-0.4 \mu \mathrm{m}$ and then tested at $823 \mathrm{~K}$ using a strain rate of $2 \times 10^{-4} \mathrm{~s}^{-1}$ with a specimen having gauge dimensions of $12 \times 3 \times 1.5 \mathrm{~mm}^{3}$ [39]. Multi-axial forging was used also to achieve a similar elongation of 
$1100 \%$ in an alloy with a grain size of $0.8 \mu \mathrm{m}$ tested at $1023 \mathrm{~K}$ using a strain rate of $7 \times 10^{-4} \mathrm{~s}^{-1}$ with gauge dimensions of $15 \times 4 \times 0.8 \mathrm{~mm}^{3}$ [40] and high temperature rolling was used to give a grain size of $1.8 \mu \mathrm{m}$ and an elongation of $1706 \%$ at $1148 \mathrm{~K}$ using a strain rate of $10^{-3} \mathrm{~s}^{-1}$ with a gauge length of $5 \mathrm{~mm}$ [41]. All of these elongations are larger than in the present investigation and the grain sizes are also consistently larger. Furthermore, the gauge lengths in each investigation are also longer since the present research used miniature tensile specimens cut from HPT disks with dimensions of $1.1 \times 1.0 \times 0.6 \mathrm{~mm}^{3}$.

In principle, it is now well established that the elongations to failure in tensile testing generally increase with decreasing gauge length $[42,43]$. This suggests, therefore, that the miniature HPTprocessed specimens should exhibit elongations that are larger rather than smaller than in the conventional specimens. This apparent inconsistency was noted in a recent study of the low temperature tensile properties of the Ti-6Al-4V alloy [31] and it arises because of the exceptionally reduced thicknesses in tensile specimens machined from HPT disks. In the present experiments, the thicknesses of the tensile specimens were only $\sim 0.6 \mathrm{~mm}$ and this means there was not sufficient grains within the specimen cross-sections to accommodate a pulling out to exceptionally high tensile elongations. The occurrence of consistently lower elongations in the tensile testing of HPT-processed samples was also noted recently in a comprehensive review of experimental data for various Al-Mg-Sc specimens [44]. Thus, the present investigation provides meaningful information on the effect on superplasticity of different initial microstructures but the results give elongations that are smaller than in the longer conventional specimens that are cut from larger billets.

\section{Summery and conclusions}

1. Two Ti-6Al-4V alloys with different initial microstructures, martensitic and lamellar, were processed by HPT through 10 turns to produce grain sizes of $\sim 30$ and $\sim 40 \mathrm{~nm}$, respectively. During HPT processing, an $f c c$-phase was formed in the martensitic alloy and the $\beta$-phase was dissolved in the lamellar alloy. 
2. These two microstructures gave excellent ductilities in tensile testing at 923-1023 K with maximum total elongations of $815 \%$ and $690 \%$ at $973 \mathrm{~K}$ for the martensitic and lamellar alloys, respectively. The occurrence of superplastic flow was confirmed by the fine equiaxed microstructures in both the undeformed grip regions and the deformed gauge sections.

3. Phase transformations of the form $\alpha^{\prime}+f c c \rightarrow \alpha+\beta+f c c$ and $\alpha \rightarrow \alpha+\beta$ occurred due to holding at high testing temperatures up to $1023 \mathrm{~K}$ in the martensitic and lamellar alloys, respectively. A $\beta$-phase precipitation acted as an accommodation mechanism and contributed to the enhancement of superplasticity. The development of an $f c c$ phase in the martensitic alloy appears to improve superplasticity by inhibiting grain growth and promoting grain boundary sliding.

\section{Acknowledgements}

This work was supported by CAPES in Brazil (PHRP) and by the European Research Council under Grant Agreement No. 267464-SPDMETALS. 


\section{References}

1- C. Hammond, Superplasticity in titanium base alloys, in: N.E. Paton, C.H. Hamilton (eds.), Superplastic Forming of Structural Alloys, The Metallurgical Society of AIME, Warrendale, PA, USA (1982) pp.131-145.

2- H.S. Yang, G. Gurewitz, A.K. Mukherjee, Mechanical behavior and microstructural evolution during superplastic deformation of Ti-6Al-4V, Mater. Trans. JIM. 32 (1991) 465472.

3- M.L. Meier, D.R. Leuser, A.K. Mukherjee, The effects of the $\alpha / \beta$ phase proportion on the superplasticity of Ti-6Al-4V and iron-modified Ti-6Al-4V, Mater. Sci. Eng. A 154 (1992) $165-173$.

4- O.A. Kaibyshev, Superplasticity of Alloys, Intermetallides, and Ceramics, first ed., Springer-Verlag, Berlin, Germany (1992).

5- A.K. Ghosh, C.H. Hamilton, Mechanical behaviour and hardening characteristics of a superplastic Ti-6Al-4V alloy, Metall. Trans. A 10A (1979) 699-706.

6- J.S. Kim, Y.W. Chang, C.S. Lee, Quantitative analysis on boundary sliding and its accommodation mode during superplastic deformation of two-phase Ti-6Al-4V alloy, Metall. Mater. Trans. A 29A (1998) 217-226.

7- T. Seshacharyulu, S.C. Medeiros, W.G. Frazier, Y.V.R.K. Prasad, Hot working of commercial Ti-6Al-4V with an equiaxed $\alpha-\beta$ microstructure: materials modeling considerations, Mater. Sci. Eng. A 284 (2000) 184-194.

8- E. Alabort, P. Kontis, D. Barba, K. Dragnevski, R.C. Reed, On the mechanisms of superplasticity in Ti-6Al-4V, Acta Mater. 105 (2016) 449-463.

9- Y.G. Ko, W.G. Kim, C.S. Lee, D.H. Shin, Microstructural influence on low-temperature superplasticity of ultrafine-grained Ti-6Al-4V alloy, Mater. Sci. Eng. A 410-411 (2005) 156-159. 
10- Y.G. Ko, C.S. Lee, D.H. Shin, S.L. Semiatin, Low-temperature superplasticity of ultra-finegrained Ti-6Al-4V processed by equal-channel angular pressing, Metall. Mater. Trans. A 37A (2006) 381-391.

11- H. Matsumoto, K. Yoshida, S-H. Lee, Y. Ono, A. Chiba, Ti-6Al-4V alloy with an ultrafinegrained microstructure exhibiting low-temperature-high-strain-rate superplasticity, Mater. Letters 98 (2013) 209-212.

12-A.P. Zhilyaev, T.G. Langdon, Using high-pressure torsion for metal processing: Fundamentals and applications, Prog. Mater. Sci. 53 (2008) 893-979.

13- A.V. Sergueeva, V.V. Stolyarov, R.Z. Valiev, A.K. Mukherjee, Enhanced superplasticiy in a Ti-6Al-4V alloy processed by severe plastic deformation, Scr. Mater. 43 (2000) 819-824.

14- R.S. Mishra, V.V. Stolyarov, C. Echer, R.Z. Valiev, A.K. Mukherjee, Mechanical behavior and superplasticity of a severe plastic deformation processed nanocrystalline Ti-6Al-4V alloy, Mater. Sci. Eng. A 298 (2001) 44-50.

15- A.V. Sergueeva, V.V. Stolyarov, R.Z. Valiev, A.K. Mukherjee, Superplastic behaviour of ultrafine-grained Ti-6A1-4V alloys, Mater. Sci. Eng. A 323 (2002) 318-325.

16- J. Fu, H. Ding, Y. Huang, P. H. R. Pereira, W. Zhang, T. G. Langdon, Grain refining of a Ti-6Al-4V alloy by high-pressure torsion and low temperature superplasticity, Letters on Materials 5 (2015) 281-286.

17- B.K. Damkroger, G.R. Edwards, Continuous cooling transformation kinetics in alpha-beta titanium alloys, in: M.P. Anderson, A.D. Rollett (eds.), Simulation and Theory of Evolving Microstructure, The Minerals, Metals and Materials Society, Warrendale, PA, USA (1990) pp. 129-152.

18- F.J. Gil, J.A. Planell, Growth order and activation energies for grain growth of Ti-6Al-4V alloy in $\beta$ phase, Scr. Metall. Mater. 25 (1991) 2843-2848. 
19- R.B. Figueiredo, P.R. Cetlin, T.G. Langdon, Using finite element modeling to examine the flow processes in quasi-constrained high-pressure torsion, Mater. Sci. Eng. A 528 (2011) 8198-8204.

20- A. Loucif, R.B. Figueiredo, M. Kawasaki, T. Baudin, F. Brisset, R. Chemam, T.G. Langdon, Effect of aging on microstructural development in an Al-Mg-Si alloy processed by high-pressure torsion, J. Mater. Sci. 47 (2012) 7815-7820.

21-T.G. Langdon, Seventy-five years of superplasticity: Historic developments and new opportunities, J. Mater. Sci. 44 (2009) 5998-6010.

22-K. Higashi, M. Mabuchi, T.G. Langdon, High-strain-rate superplasticity in metallic materials and the potential for ceramic materials, ISIJ Intl. 36 (1996) 1423-1438.

23- H. Ishikawa, F.A. Mohamed, T.G. Langdon, The influence of strain rate on ductility in the superplastic Zn-22\% Al eutectoid, Phil. Mag. 32 (1975) 1269-1271.

24- T.G. Langdon, A unified approach to grain boundary sliding in creep and superplasticity, Acta Metall. Mater. 42 (1994) 2437-2443.

25- B.D. Cullity, S.R. Stock, Elements of X-ray Diffraction. 3rd Ed, Prentice Hall, Englewood Cliffs, NJ, USA (2001).

26- F.J. Gil, J.M. Manero, J.A. Planell, Decomposition of $\alpha^{\prime}$ martensite plates of Ti-6Al-4V alloy at different annealing temperatures and heat treatment times, in: P.A. Blankensop, W.J. Evans, H.M. Flower (eds.), Titanium 1995, Science and Technology, The Institute of Materials, London, UK, (1996) pp. 2454-2461.

27- D.H. Shin, I. Kim, J. Kim, Y.T. Zhu, Shear strain accommodation during severe plastic deformation of titanium using equal channel angular pressing, Mater. Sci, Eng. A 334 (2002) 239-245.

28- D.H. Shin, I. Kim, J. Kim, Y.S. Kim, and S.L. Semiatin, Microstructure development during equal-channel angular pressing of titanium, Acta Mater. 51 (2003) 983-996. 
29- S.V. Zherebtsov, G.S. Dyakonov, A.A. Salem, S.P. Malysheva, G.A. Salishchev, S.L. Semiatin, Evolution of grain and subgrain structure during cold rolling of commercialpurity titanium, Mater. Sci. Eng. A 528 (2011) 3474-3479.

30- H. Shahmir, T.G. Langdon, An evaluation of the hexagonal close-packed to face-centered cubic phase transformation in a Ti-6Al-4V alloy during high-pressure torsion, Mater. Sci. Eng. A 704 (2017) 212-217.

31-H. Shahmir, T.G. Langdon, Using heat treatments, high-pressure torsion and postdeformation annealing to optimize the properties of Ti-6Al-4V alloys, Acta Mater. 141 (2017) 419-426.

32- F.X. Gil Mur, D. Rodríguez, J.A. Planell, Influence of tempering temperature and time on the $\alpha^{\prime}$-Ti-6A1-4V martensite, J. Alloy. Compds 234 (1996) 287-289.

33-T.G. Langdon, An evaluation of the strain contributed by grain boundary sliding in superplasticity, Mater. Sci. Eng. A 174 (1994) 225-230.

34- M. Meier, A. Mukherjee, Consequences of using the average diffusivity in correlating the enhanced superplasticity of iron-modified Ti-6Al-4V, Scr. Metall. Mater. 25 (1991) 14711476.

35- S.L. Semiatin, F. Montheillet, G. Shen, J.J. Jonas, Self-consistent modeling of the flow behavior of wrought alpha/beta titanium alloys under isothermal and nonisothermal hotworking conditions, Metall. Mater. Trans. A 33 (2002) 2719-2727.

36- F.A. Mohamed, T.G. Langdon, The transition from dislocation climb to viscous glide in creep of solid solution alloys, Acta Metall. 22 (1974) 779-788.

37- G.A. Salishchev, O.R. Valiakhmetov, V.A. Valitov, S.K. Mukhtarov, Submicrocrystalline and nanocrystalline structure formation in materials and search for outstanding superplastic properties, Mater. Sci. Forum 170-172 (1994) 121-130. 
38- H. Shahmir, J. He, Z. Lu, M. Kawasaki, T.G. Langdon, Evidence for superplasticity in a CoCrFeNiMn high-entropy alloy processed by high-pressure torsion, Mater. Sci. Eng. A, 685 (2017) 342-348.

39-S.V. Zherebtsov, E.A. Kudryavtsev, G.A. Salishchev, B.B. Straumal, S.L. Semiatin, Microstructure evolution and mechanical behavior of ultrafine Ti-6Al-4V during lowtemperature superplastic deformation, Acta Mater. 121 (2016) 152-163.

40- G.A. Salishchev, R.M. Galeyev, O.R. Valiakhmetov, R.V. Safiullin, R.Y. Lutfullin, O.N. Senkov, F.H. Froes, O.A. Kaibyshev, Development of Ti-6Al-4V sheet with low temperature superplastic properties, J. Mater. Proc. Tech. 116 (2001) 265-268.

41-C.H. Park, Y.G. Ko, J.W. Park, C.S. Lee, Enhanced superplasticity utilizing dynamic globularization of Ti-6Al-4V alloy, Mater. Sci. Eng. A 496 (2008) 150-158.

42- Y.H. Zhao, Y.Z. Guo, Q. Wei, A.M. Dangelewicz, C. Xu, Y.T. Zhu, T.G. Langdon, Y.Z. Zhou, E.J. Lavernia, Influence of specimen dimensions on the tensile behavior of ultrafinegrained Cu, Scr. Mater. 59 (2008) 627-630.

43- Y.H. Zhao, Y.Z. Guo, Q. Wei, T.D. Topping, A.M. Dangelewicz, Y.T. Zhu, T.G. Langdon, E.J. Lavernia, Influence of specimen dimensions and strain measurement methods on tensile stress-strain curves, Mater. Sci. Eng. A 525 (2009) 68-77.

44- P.H.R. Pereira, Y.Huang, M. Kawasaki, T.G. Langdon, An examination of the superplastic characteristics in Al-Mg-Sc alloys after processing, J. Mater. Res. (2017) DOI: 10.1557/jmr.2017.286. 


\section{Table caption}

Table 1. Summary of experimental parameters and elongations to failure $(\delta)$ in investigations of Ti-6Al-4V processed by HPT $[13,15,16]$.

\section{Figures captions}

Fig. 1 Optical micrograph of the microstructure for Ti-6Al-4V after (a) annealing at $1273 \mathrm{~K}$ for 30 min followed by water quenching ( $\alpha^{\prime}$ alloy) and (b) after annealing at $1223 \mathrm{~K}$ for 30 followed air quenching and then annealing at $873 \mathrm{~K}$ for $3 \mathrm{~h}$ followed by furnace quenching $(\alpha+\beta$ alloy). TEM images of (c) $\alpha^{\prime}$ and (d) $\alpha+\beta$ alloys after 10 turns HPT processing.

Fig. 2 Values of the Vickers microhardness measured across disks of $\alpha^{\prime}$ and $\alpha+\beta$ alloys processed through 10 turns at a rotation speed of $1 \mathrm{rpm}$ : the lower dashed lines show the hardness of the initial conditions.

Fig. 3 Engineering stress-elongation curves at different temperatures at initial strain rate of $1.0 \times 10^{-2} \mathrm{~s}^{-1}$ for (a) $\alpha^{\prime}$ and (b) $\alpha+\beta$ samples processed by HPT.

Fig. 4 Engineering stress-elongation curves after testing at $973 \mathrm{~K}$ at initial strain rate of $1.0 \times 10^{-}$ ${ }^{3}$ to $1.0 \times 10^{-1} \mathrm{~s}^{-1}$ for (a) $\alpha^{\prime}$ and (b) $\alpha+\beta$ samples processed by HPT.

Fig. 5 Maximum stress plotted against initial strain rate to determine strain rate sensitivity, $m$. Fig. $6 \mathrm{X}$-ray patterns in the grip sections after tensile testing at 923,973 and $1023 \mathrm{~K}$ with an initial strain rate of $1.0 \times 10^{-3} \mathrm{~s}^{-1}$ of HPT-processed (a) $\alpha^{\prime}$ and (b) $\alpha+\beta$ alloys.

Fig. 7 SEM images in the (a) gauge and (b) grip sections after tensile testing at $973 \mathrm{~K}$ with an initial strain rate of $1.0 \times 10^{-3} \mathrm{~s}^{-1}$ corresponding to an elongation of $\sim 810 \%$ for the $\alpha^{\prime}$ sample processed by HPT through 10 turns: arrows in the microstructure show the presence of a primary $\alpha$ grain and a lamellar $\alpha+\beta$ grain and the tensile directions (TD) are indicated.

Fig. 8 EBSD inverse-pole-figure (IPF) maps and corresponding pole figures (basal $\{0001\}$ planes) of (a,b) martensitic and (c,d) lamellar alloys in the gauge (left) and grip (right) areas after tensile testing at $973 \mathrm{~K}$ with an initial strain rate of $1.0 \times 10^{-3} \mathrm{~s}^{-1}$. 


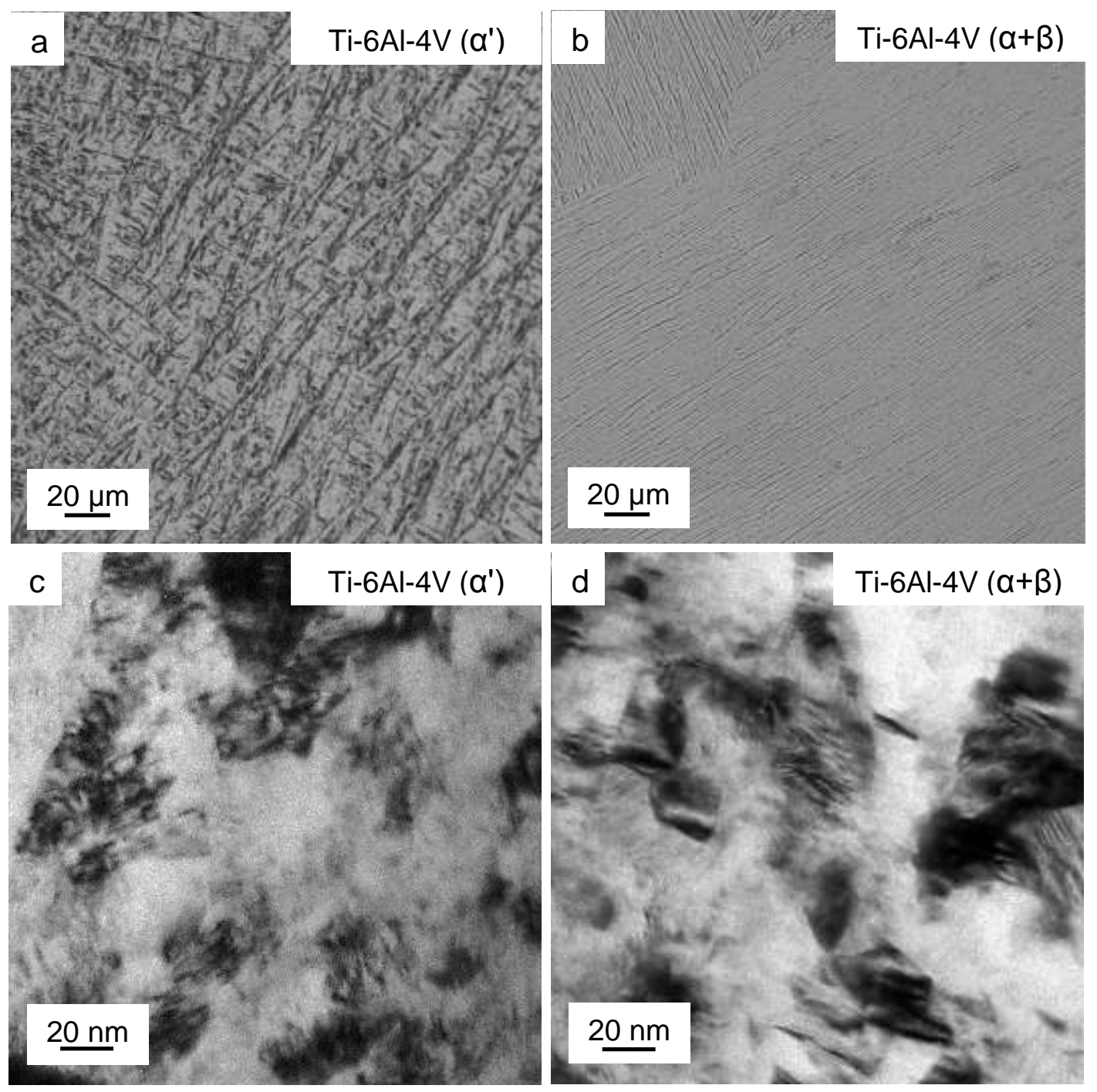

Fig. 1 Optical micrograph of the microstructure for Ti-6Al-4V after (a) annealing at $1273 \mathrm{~K}$ for $30 \mathrm{~min}$ followed by water quenching ( $\alpha^{\prime}$ alloy) and after (b) annealing at $1223 \mathrm{~K}$ for 30 followed air quenching and then annealing at $873 \mathrm{~K}$ for $3 \mathrm{~h}$ followed by furnace quenching $(\alpha+\beta$ alloy).

TEM images of (c) $\alpha^{\prime}$ and (d) $\alpha+\beta$ alloys after 10 turns HPT processing. 


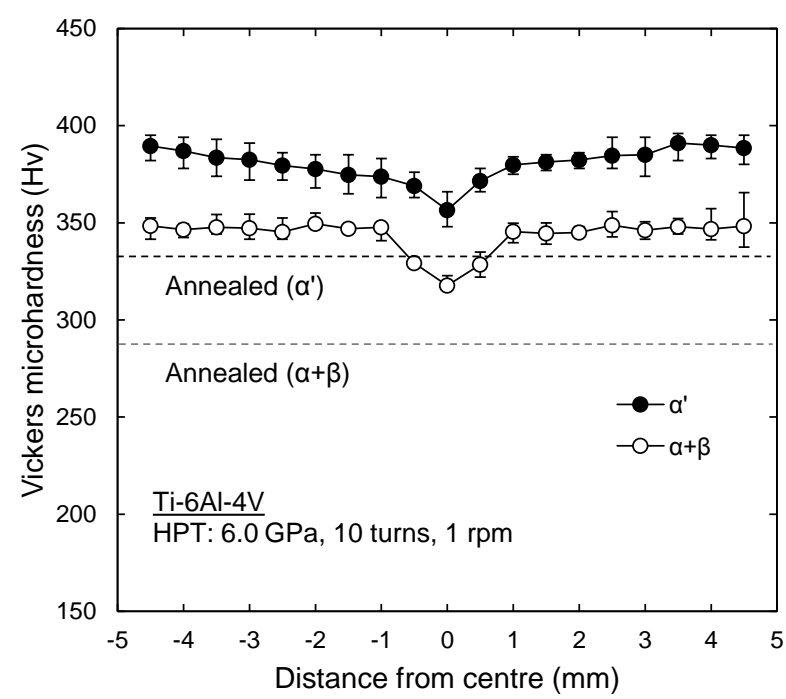

Fig. 2 Values of the Vickers microhardness measured across disks of $\alpha^{\prime}$ and $\alpha+\beta$ alloys processed through 10 turns at a rotation speed of $1 \mathrm{rpm}$ : the lower dashed lines show the hardness of the initial conditions. 

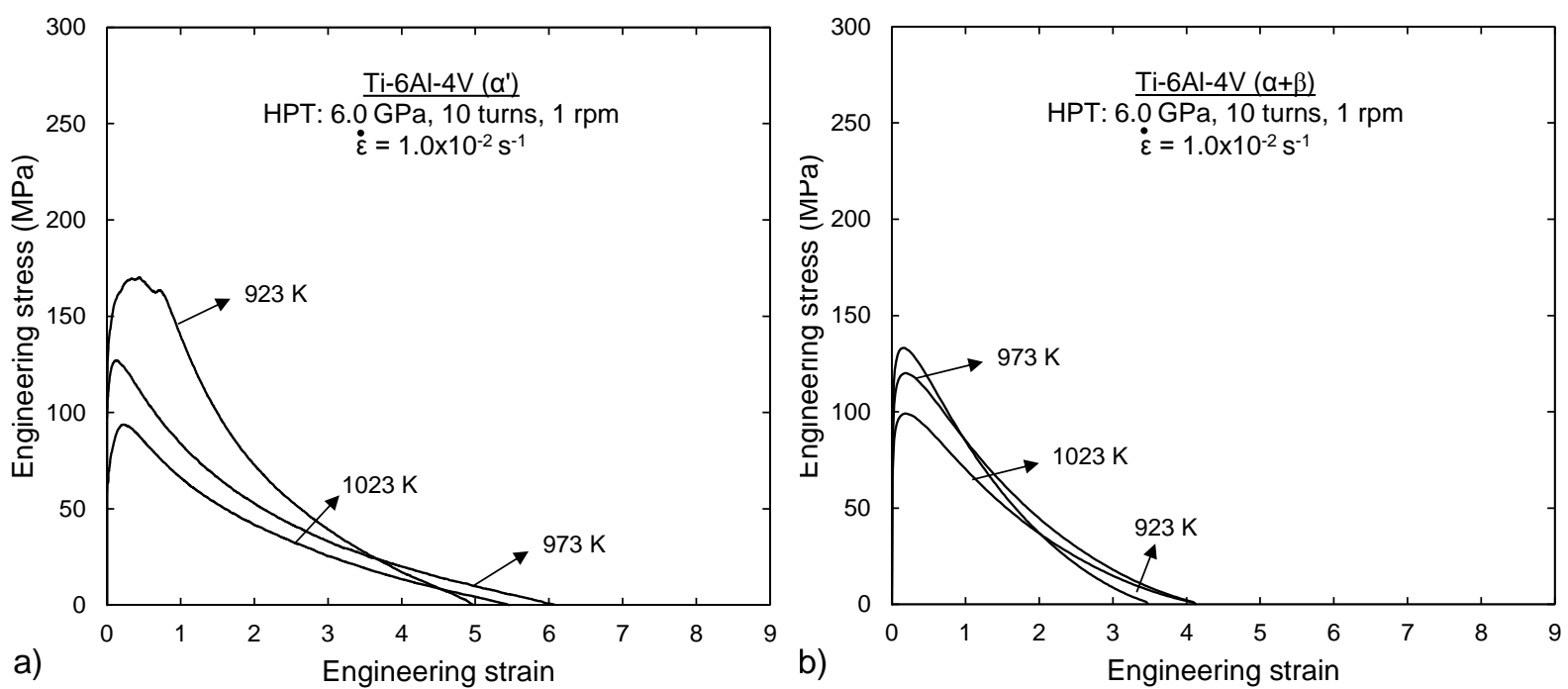

Fig. 3 Engineering stress-elongation curves at different temperatures at initial strain rate of $1.0 \times 10^{-2} \mathrm{~s}^{-1}$ for (a) $\alpha^{\prime}$ and (b) $\alpha+\beta$ samples processed by HPT. 

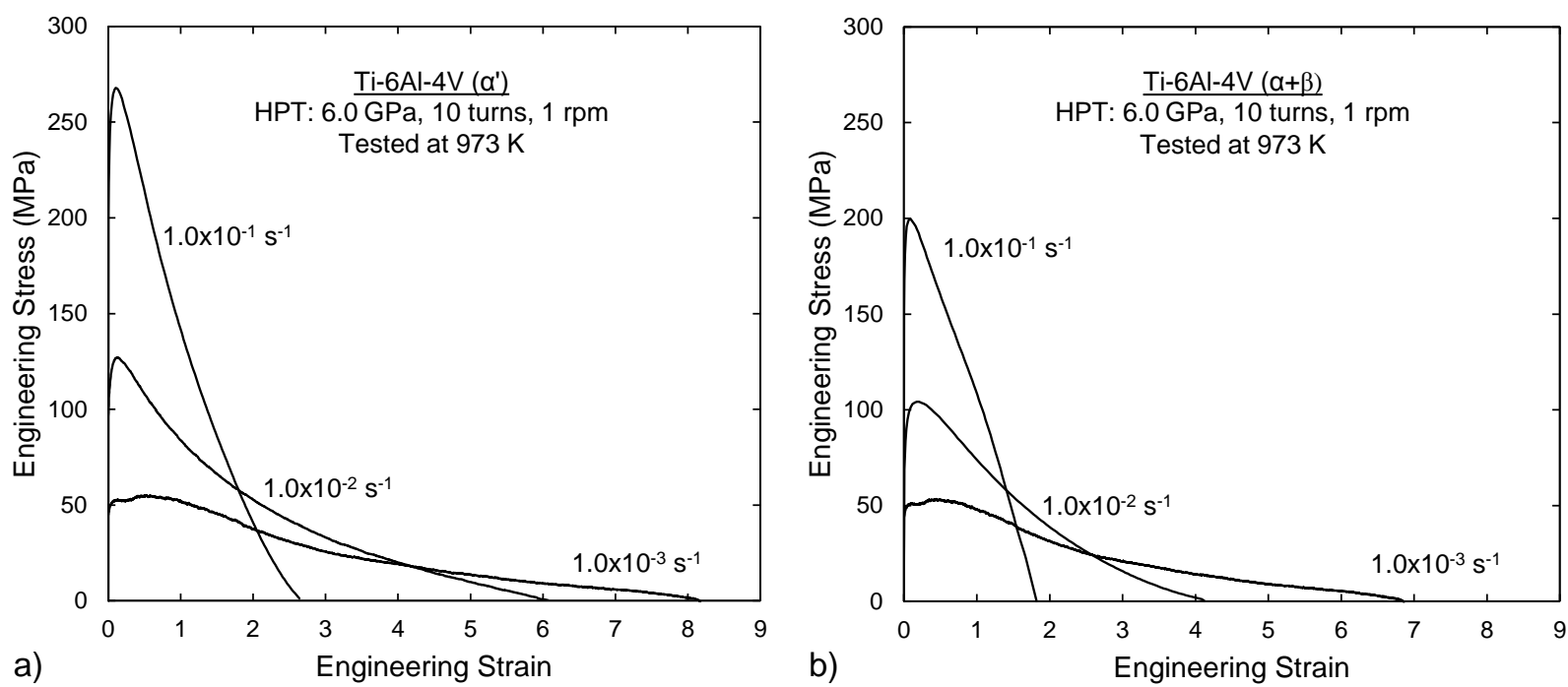

Fig. 4 Engineering stress-elongation curves after testing at $973 \mathrm{~K}$ at initial strain rate of $1.0 \times 10^{-3}$ to $1.0 \times 10^{-1} \mathrm{~s}^{-1}$ for (a) $\alpha^{\prime}$ and (b) $\alpha+\beta$ samples processed by HPT. 


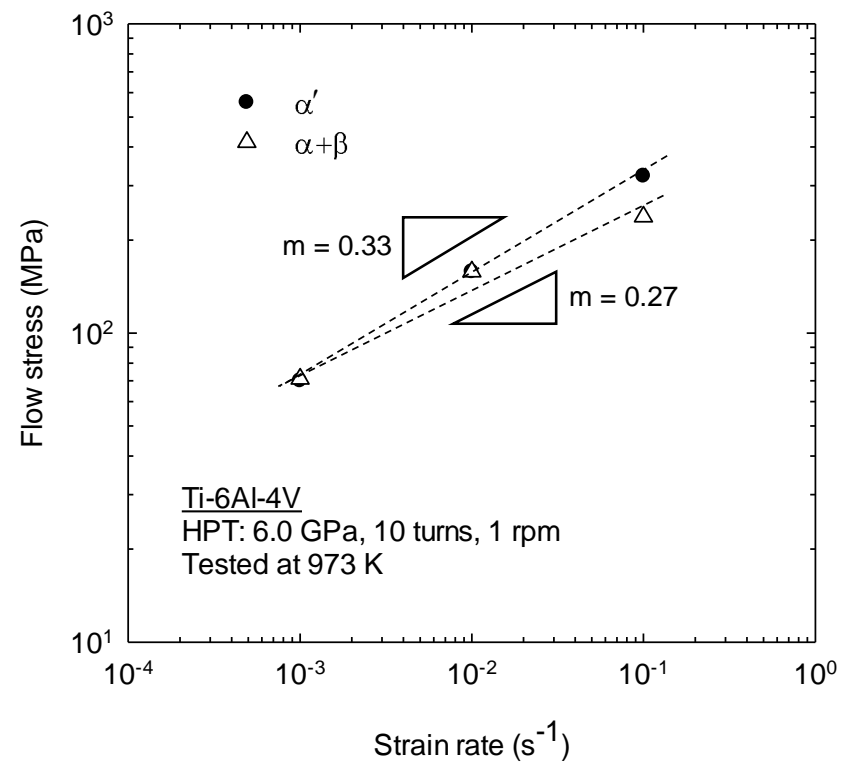

Fig. 5 Maximum stress plotted against initial strain rate to determine strain rate sensitivity, $m$. 

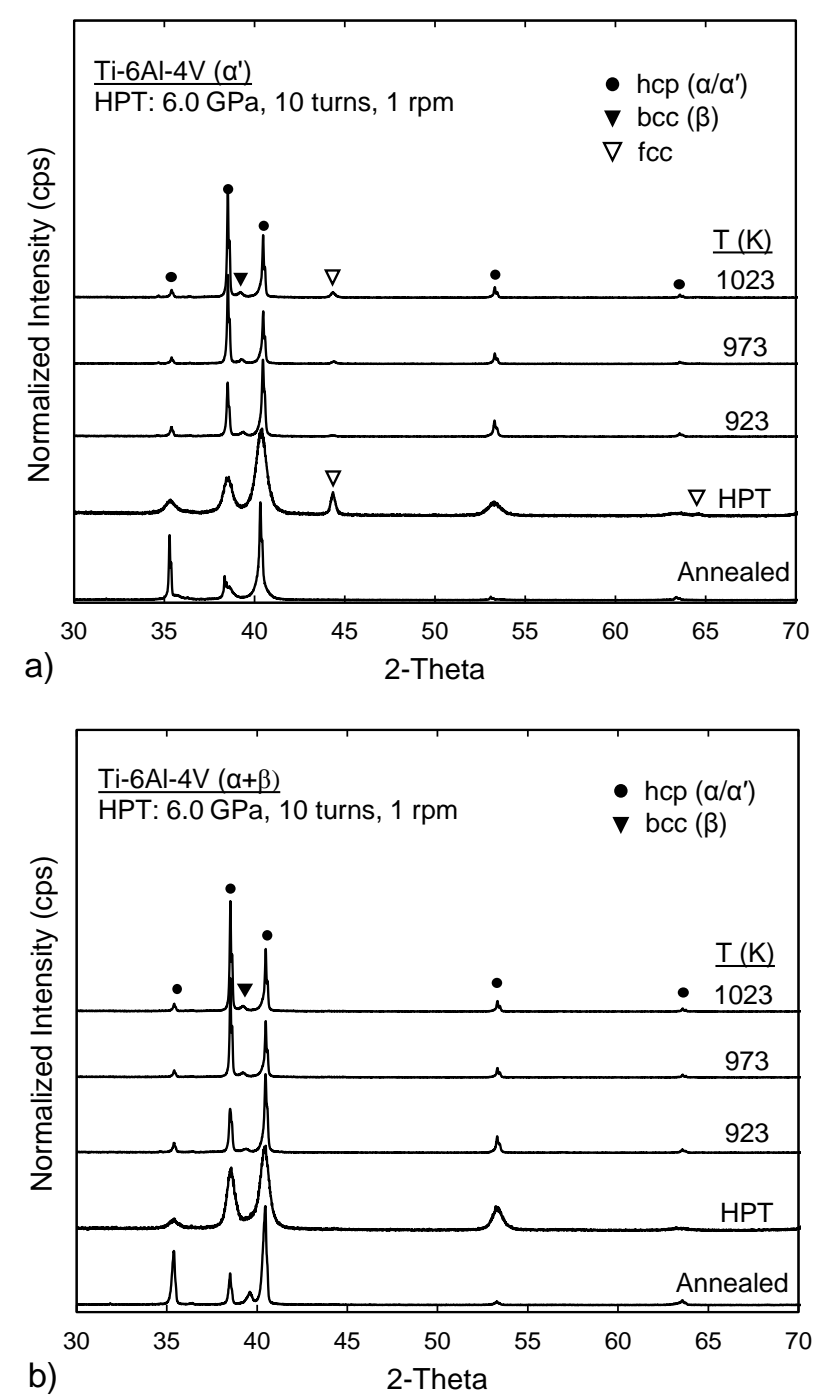

Fig. 6 X-ray patterns in the grip sections after tensile testing at 923, 973 and $1023 \mathrm{~K}$ with an initial strain rate of $1.0 \times 10^{-3} \mathrm{~s}^{-1}$ of HPT-processed (a) $\alpha^{\prime}$ and (b) $\alpha+\beta$ alloys. 


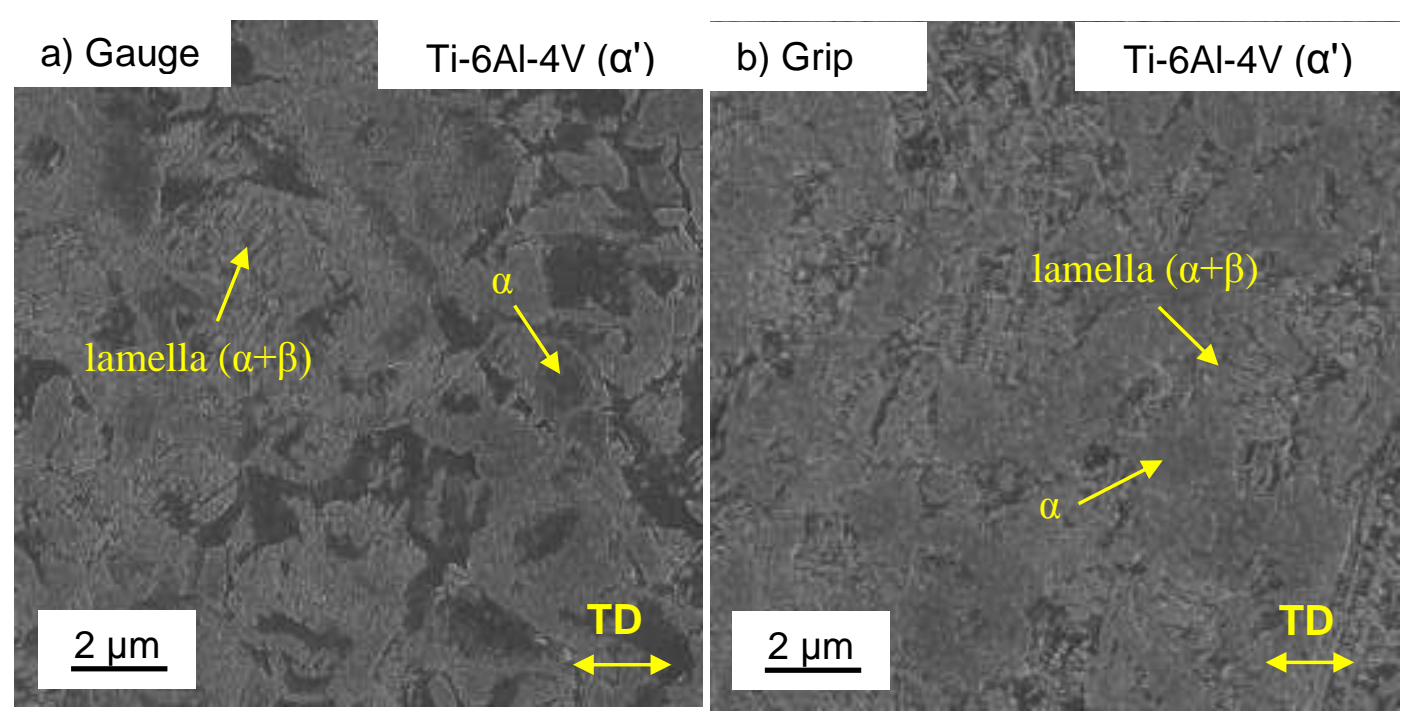

Fig. 7 SEM images in the (a) gauge and (b) grip sections after tensile testing at $973 \mathrm{~K}$ with an initial strain rate of $1.0 \times 10^{-3} \mathrm{~s}^{-1}$ corresponding to an elongation of $\sim 810 \%$ for the $\alpha^{\prime}$ sample processed by HPT through 10 turns: arrows in the microstructure show the presence of a primary $\alpha$ grain and a lamellar $\alpha+\beta$ grain and the tensile directions (TD) are indicated. 

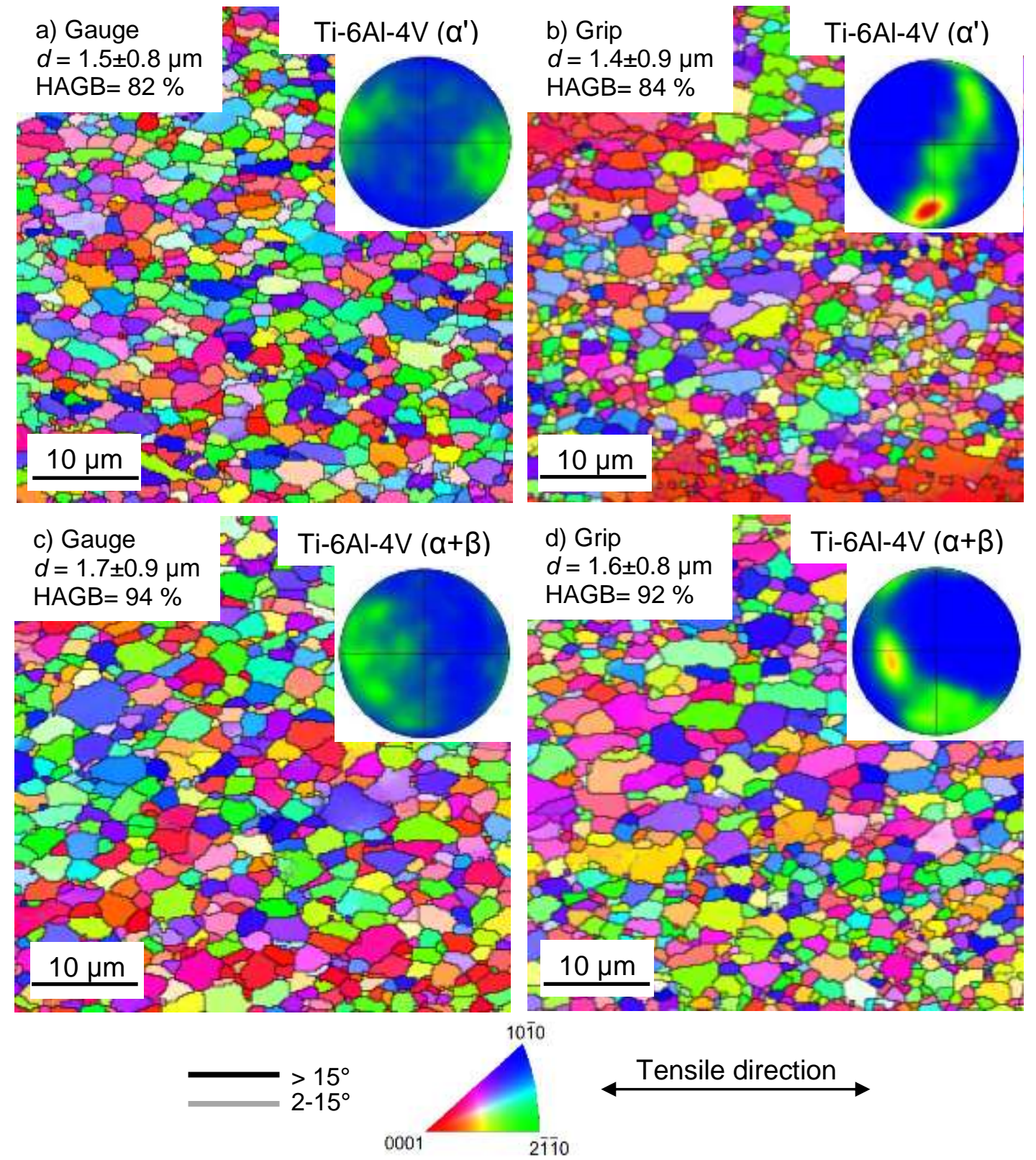

Fig. 8 EBSD inverse-pole-figure (IPF) maps and corresponding pole figures (basal $\{0001\}$ planes) of (a,b) martensitic and (c,d) lamellar alloys in the gauge (left) and grip (right) areas after tensile testing at $973 \mathrm{~K}$ with an initial strain rate of $1.0 \times 10^{-3} \mathrm{~s}^{-1}$. 
Table 1. Summary of experimental parameters and elongations to failure $(\delta)$ in investigations of Ti-6Al-4V processed by HPT $[13,15,16]$.

\begin{tabular}{ccccc}
\hline Initial microstructure & Temperature $(\mathrm{K})$ & Strain rate $\left(\mathrm{s}^{-1}\right)$ & $\delta(\%)$ & Ref. \\
\hline$\alpha+$ lamellar $(\alpha+\beta)$ & 923 & $1.0 \times 10^{-3}$ & 575 & Sergueeva et al. $[13]$ \\
\hline$\alpha+$ lamellar $(\alpha+\beta)$ & 923 & $1.0 \times 10^{-3}$ & 568 & Sergueeva et al. $[15]$ \\
\hline $75 \%$ lamellar $(\alpha+\beta)+$ & 998 & $1.0 \times 10^{-2}$ & 504 & \\
$\alpha$ & 998 & $1.0 \times 10^{-3}$ & 676 & \\
\hline Lamellar $(\alpha+\beta)$ & 873 & $1.0 \times 10^{-3}$ & 540 & Fu et al. [16] \\
& 973 & $1.0 \times 10^{-4}$ & 790 & \\
\hline Martensite $\alpha^{\prime}$ & 973 & $1.0 \times 10^{-2}$ & 410 & This investigation \\
& 923 & $1.0 \times 10^{-3}$ & 690 & \\
\hline & 973 & $1.0 \times 10^{-2}$ & 500 & This investigation \\
& 973 & $1.0 \times 10^{-2}$ & 610 & \\
\hline
\end{tabular}

